\title{
Diagnostic Methods for an Aircraft Engine Performance
}

\author{
E. L. Ntantis* and P. N. Botsaris
}

Department of Production Engineering \& Management, Polytechnic School of Engineering, Democritus University of Thrace, 67100, Xanthi, Greece

Received 24 September 2015; Accepted 19 November 2015

\begin{abstract}
The main gas path components, namely compressor and turbine, are inherently reliable but the operation of the aero engines under hostile environments, results into engine breakdowns and performance deterioration. Performance deterioration increases the operating cost, due to the reduction in thrust output and higher fuel consumption, and also increases the engine maintenance cost. In times when economic considerations dominate airline operators' strategies, carrying out unnecessary rectification, can be very costly and time consuming. In an attempt to minimize such unexpected circumstances, having detailed knowledge prior to any inspection will allow the gas turbine user to take some of the maintenance action when it is necessary. Advanced engine-fault diagnostics tools offer the possibility of identifying degradation at the module level, determining the trends of these degradations during the usage of the engine, and planning the maintenance action ahead.
\end{abstract}

Keywords: aircraft, gas turbine, diagnostic methods, physical faults, performance deterioration

\section{Introduction}

The performance of an aircraft gas turbine is highly dependent on the aerodynamics and thermodynamics of every single component due to its complexity as a machine. The main gas path components, namely compressor and turbine, are inherently reliable but the operation of the aero engines under hostile environments, such as varying conditions of load, temperature and speed, and the cycle sensitivity to component degradation, results into engine breakdowns and performance deterioration [1-6]. The effect of component degradation is that the efficiencies and capacities of these get changed, and in order to determine the degradation level, it is required to estimate the level of changes in efficiency and capacity $[1,7,8]$. Performance deterioration is inevitable; increases engine maintenance cost and ultimately affects the safety of the engine, the aircraft and the crew. A deteriorated engine also increases the operating cost, due to the reduction in thrust output and higher fuel consumption. In order to keep the same thrust level of a clean engine, the engine reaches higher spool speeds and running temperatures that shorten the life span of various components.

In times when economic considerations dominate airline operators' strategies, carrying out unnecessary rectification, such as replacing a fine or not taking action to a faulty component, can be very costly and time consuming. In an attempt to minimize such unexpected circumstances, having detailed knowledge prior to any inspection will allow the gas turbine user to take some of the maintenance action when it

* E-mail address: entantis@gmail.com ISSN: 1791-2377 @ 2015 Kavala Institute of Technology. All rights reserved. is necessary, reducing downtime and increasing the availability of the engine. Maintenance action is the process, to ensure that the gas turbine systems continually perform the intended function, at its designed level of reliability and safety. These condition monitoring systems, examples are described in $[9,10]$, gather measurements data periodically from the engine instrumentation in service and then process information that can optimize both the subsequent operation of the gas turbine and the maintenance, repair and overhaul [11]. Advanced engine-fault diagnostics tools offer the possibility of identifying degradation at the module level, determining the trends of these degradations during the usage of the engine, and planning the maintenance action ahead. Therefore the purpose of monitoring systems is to extent to which it can enable the proper deduction of engine faults and minimize the total life cycle costs [88-96].

\section{Physical Faults}

It is useful to examine a number of physical faults that may exist in the gas path of the gas turbine, affecting seriously the component and therefore the overall performance of the engine. The physical faults presented in Table 1 and discussed in details.

Fouling: Fouling is one of the commonest causes of performance reduction encountered by users of gas turbines $[4,12]$ and can count for more than $70 \%$ of the performance loss during operation [2]. Particular contaminants (dirt, dust, oil, pollen, salt etc.) have the tendency to stick to the airfoil surface and change the aerofoil inlet angle, aerofoil shape, increase surface roughness and narrowing airfoil throat aperture [2], causing the degradation of gas path components' pumping capacity and efficiency [13]. The decrease in mass flow will result in a decrease in thrust 


\section{Journal of Engineering Science and Technology Review 8 (4) (2015) 64- 72}

necessitating an increase in the rotational speed to maintain a required thrust level, while the decrease in isentropic efficiency will cause an increase in TET $[2,3,14]$ and SFC, thereby reducing the engine life and increasing the engine operating costs. Performance deterioration due to fouling is recoverable by cleaning/washing; when the mass flow decreases by approximately $2.5 \%$ [2].

Table 1. Effect of physical faults on components' performance

\begin{tabular}{|lll|}
\hline \multicolumn{3}{|c|}{ Physical Effect on Component Performance } \\
\hline Fouling & Drop in compressor and turbine flow capacity & $0.0-[-5.0 \%]$ \\
& Drop in compressor and turbine efficiency & $0.0-[-2.5 \%]$ \\
\hline Corrosion & Drop in compressor flow capacity & $0.0-[-5.0 \%]$ \\
& Rise in turbine flow capacity & $0.0-[+5.0 \%]$ \\
& Drop in compressor and turbine efficiency & $0.0-[-2.5 \%]$ \\
\hline Erosion & Drop in compressor flow capacity & $0.0-[-5.0 \%]$ \\
& Rise in turbine flow capacity & $0.0-[+5.0 \%]$ \\
& Drop in compressor and turbine efficiency & $0.0-[-2.5 \%]$ \\
\hline FOD/DOD & Drop in compressor and turbine efficiency & $0.0-(-5.0 \%)$ \\
\hline
\end{tabular}

Corrosion: The chemical reaction between flow path components and contaminants that enters the gas turbine with the inlet air, fuel or injected water/stream, causes corrosion that is the loss of material from those gas path components [2]. Turbine blades are more susceptible to corrosion due to the presence of combustion products and elevated temperatures. The effect of corrosion is quite similar to the effect of erosion, since there is a loss of material, increase of surface roughness that leads to reduction of the component performance and isentropic efficiency. An effective protection from corrosion attack and subsequent loss of performance for both compressor and turbine is through coating.

Erosion: Operators flying in sandy or dusty environments suffer from the phenomenon of erosion. Most of the ingested dust particles in a desert environment are found to have sizes of $0-1000 \mu \mathrm{m}$ [15]. Erosion is caused by, the abrasive removal of material from the gas path components by hard particles suspended in the air stream. Erosion leads to increased blade surface roughness, blade tip, seal clearance and changes in the inlet metal angle, airfoil profile, throat opening and blade surface pressure distribution. In compressors due to pressure loss, there is drop of mass flow capacity and component efficiency $[3,16]$. In turbines there is a drop in efficiency but due to larger passing area, flow capacity increases and less back pressure produced on the compressor [17]. In contrast to the case of fouling erosion is non-recoverable by washing or cleaning.

FOD: FOD is the result of a body striking the internal surfaces of the gas path components of the gas turbine. The origin of such particles can be via fan section, with air or broken particles from the engine inside being carried downstream [12]. A small dent or nick to the leading edge of attacked blades can cause a stress concentration that may develop into a fatigue crack and threaten the integrity of the blades and therefore the whole engine. The impact of larger object damage increases the throat area, altering the surface roughness and resulting reduction in both flow capacity and efficiency.

Air leakage: Air leakage on gas turbines refers to the leak of a duct or other mechanical containment of the engine (e.g. compressor), to the outer environment.

Rubbing wear: Rubbing wear is the removal of material from the rotor blade tips and knife edges seal, due to contact between static and rotating parts that happens in both compressors and turbines.

Hot end component damage: The very high temperatures in turbines can eventually cause damage at the trailing edges of the NGVs and rotor blades, because these parts are thin and difficult to cool.

Labyrinth seal damage: The damage to the seals e.g. due to aging, increases the internal leakage between the discharge and suction side of the compressors and turbines.

Increase tip clearance: Typical reason for the increased tip clearance is the thermal expansion. This effect can be accentuated by casing and shaft distortion, which is susceptible to high $G$ loadings during combat flight maneuvers, as well as to turbulence and heavy landings.

Seal erosion: Any wear in the seals results in localized heating and an increase in compressor bleed air.

\section{Diagnostic Methods}

\subsection{Gas Path Analysis (GPA)}

Gas Path Analysis (GPA) pioneered by Urban $[18,19,52,53]$, is used to assess the condition of individual engine components based, on the aero-thermodynamic relationships that exist between the component and direct measurements of gas path parameters [49]. The theory behind this relationship is shown in the conceptual framework in Fig.1 which can be summarised by: The presence of a primary gas-path physical fault induces change in the component characteristic that shows up a deviation of the measurable parameters from the baseline conditions [12]. Therefore, the purpose of the GPA is to detect, isolate and quantify the gas path components faults that have observable impacts on the measurable variables with the hope that will facilitate the subsequent isolation of the underlying physical fault [83-87].

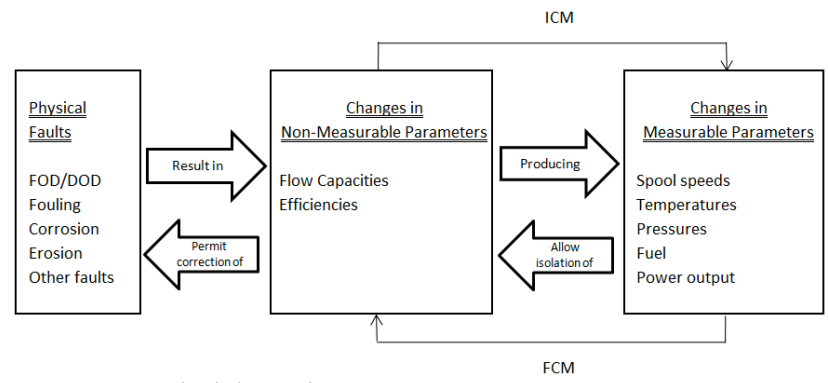

Fig. 1. GPA Principle Engine

In an arbitrary gas-turbine configuration, the mathematical relationship between dependent and independent parameters is expressed analytically in Eq.1 [12]:

$\vec{z}=h(\vec{x}, \vec{w})$

\section{Linear GPA}

To simplify the non-linear relationship between components and measurable performance parameters, a linear approximation is introduced and can be expressed in matrix form, based on the assumption that the changes in the health parameters are very small and an operation point (e.g. maximum power or cruise) is selected. Given a steady state operating point, there is no deviation from standard ambient and nominal operating conditions, and so the measurement 


\section{Journal of Engineering Science and Technology Review 8 (4) (2015) 64- 72}

values depends only on the health condition of engine (neglecting any effect of measurement noise and bias).

\section{$\Delta z=I C M \cdot \Delta x$}

The health parameters deviation can be calculated by the inversion of the ICM matrix, named as "Fault Coefficient Matrix" (FCM) by using Eq.2:

$$
\Delta x=F C M \cdot \Delta z
$$

ICM inversion to FCM is dependent on the number of performance parameters that should be less than or equal to the number of measurements, otherwise estimation techniques should be used. The whole basis of this linear GPA method is the assumption that the ICM is invertible and the measurements are noise-free. Investigation of the newer techniques, each with an ability to take into account the noise and possible sensor bias, while preserving the nonlinearity of the behaviour, led to the development of engine diagnostics based on optimisation techniques [80].

\section{Non-linear GPA}

The assumption of linearity becomes increasingly false, when deteriorations cause the engine to operate further away from the condition for which the matrix was calculated [20]. The development of non-linear GPA addresses the nonlinear nature of Eq.1 and provides a significant advantage on the severe limitations of linear GPA models. The nonlinearity of the engine thermodynamic behaviour is taken into account, by using the Newton-Raphson iterative technique, where linear prediction process is applied iteratively, until a converged solution is obtained [11].

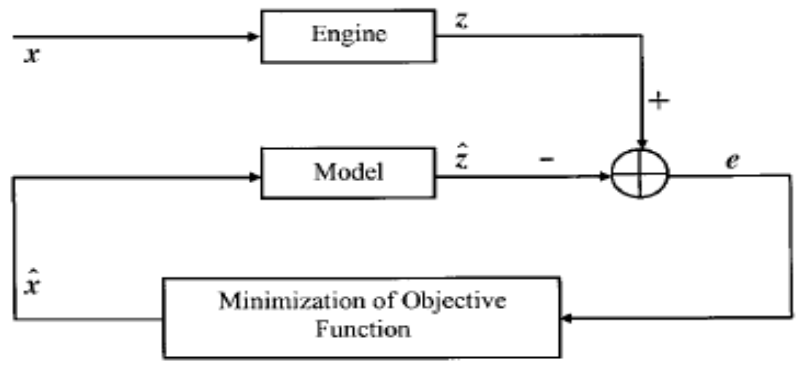

Fig. 2. Non-linear diagnostic model [47]

Fig.2 demonstrates the idea of the non-linear model based method. The real engine component parameter vector $x$ determines engine performance represented by the measurement vector $z$. With an initial guessed parameter vector $\hat{x}$ the model engine provides a predicted performance measurement vector $\hat{z}$. An optimisation approach is applied to minimise an objective function, which describes the relative difference between the predicted measurement vector $\hat{z}$ and the actual measurement vector $z$. A minimisation of the objective function is carried out iteratively until diagnostic error $e$ from the iteration process is very small and thus the best predicted engine component parameter vector is obtained.

$e_{i}=\frac{z_{i, p r e d i c t e d}-z_{i, \text { actual }}}{z_{i, \text { actual }}} \cdot 100 \%$
In particular, the convergence process is completed when Root-Mean-Square (RMS) is equal or lower to the convergence criteria $\delta$ [27]. The convergence criterion $\delta$ is a very small number, around 0.01 or less, and is being used through all the non-linear GPA calculations. However, this advantage comes at the expense of an increased computational time, due to the number of iterations required in order to get satisfactory result.

$$
R M S=\sqrt{\frac{\Delta z_{\text {sum }}^{2}}{M}}=\sqrt{\frac{\sum_{i=1}^{M}\left|z_{i, p r e d i c t e d}-z_{i, \text { actual }}\right|^{2}}{M}} \leq \delta
$$

Fig.3 illustrates the improvement on the accuracy of predicted deviation of component parameters on using nonlinear over linear. For the non-linear technique, the exact solution is found much higher than the solution obtained by linear GPA.
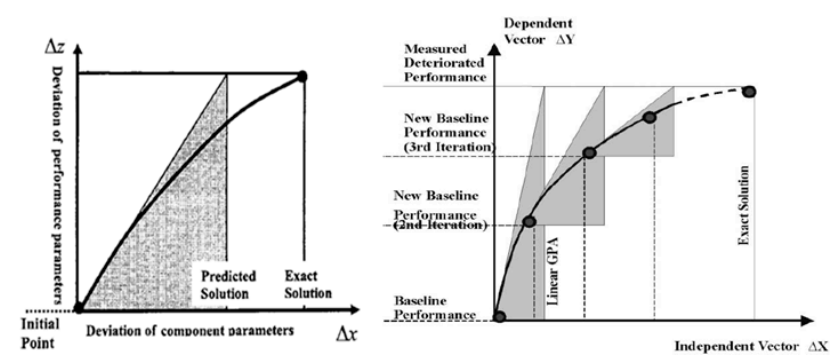

Fig.3. Prediction of component parameter with linear and non-linear GPA [21]

\subsection{Kalman Filters}

In 1960, Kalman published a recursive solution to the discrete data linear filtering problem [22] and in 1961, Kalman and Bucy followed up a paper on the continuoustime version [23]. The filter was finally called the Kalman Filter, although Shet and Rao argued that it is an algorithm rather than a filter [24]. Kalman Filter (KF) is an optimal recursive data processing algorithm, used in order to provide an estimation of the health of the engine components in presence of measurement noise and sensor bias $[22,25,26]$. A KF processes all available measurement data regardless of their precision, plus prior knowledge about the system and measuring devices, to produce an estimate of the desired variables in such a manner that the error is minimized statistically [81]. After a run of a number of candidate filters many times for the same application, the average results of the KF would be better than the average results of any other [54-58].

Measuring
devices $\stackrel{\begin{array}{c}\text { Observed } \\ \text { measurements }\end{array} \text { Kalman Filter }}{\begin{array}{c}\text { Optimal estimate } \\ \text { of system state }\end{array}}$

Fig. 4. Typical application of the Kalman Filter

The linear algorithm of KF based on two mechanisms:

- Prediction: This step is used to propagate the internal state of the system. At time step $\mathrm{k}$, the filter predicts the value of the internal state vector at the next time step $\mathrm{k}+1$.

- Correction: This step is responsible for fine-tuning the prediction step under the influence of external observations. At time $\mathrm{k}+1$ when an actual 


\section{Journal of Engineering Science and Technology Review 8 (4) (2015) 64- 72}

measurement is available, the filter corrects itself based on the prediction error. This correction is done by minimizing the error covariance.

Although, the Kalman Filter is a successful method for tracking and estimation, its application to non-linear systems can be difficult. Bearing in mind that, most of applications of interest the system dynamics and observation equations are non-linear, a suitable extension to the KF has to be sought. The most common approach to non-linear systems is the Extended Kalman Filters (EKF) and the Iterated Extended Kalman Filters (IEKF) [59-61]. The EKF and IEKF apply to non-linear systems by simply linearising all the non-linear models so that the traditional linear $\mathrm{KF}$ equation can be applied. However both produce biased and sub-optimal estimates, due to the linearization of the functions which leads to a low accuracy estimation.

\subsection{Genetic Algorithms}

First pioneered by H.J Holland in the 1960 at University of Michigan, Genetic Algorithms (GA) has been widely studied, experimented and applied in many engineering fields. The basic concept of GA is designed to simulate processes in natural system necessary for evolution, specifically those that follow the principles first laid down by Charles Darwin of survival of the fittest. The GAs is applied as an effective optimization tool to obtain a set of components parameters that produce a set of predicted dependent parameters, through a non-linear gas turbine model that leads to predictions which best match the measurements [20,48]. The solution is obtained when an objective function which is a measure of difference between predicted and measured parameters, achieves its minimum value $[78,79]$.

A diagnostic algorithm based on $\mathrm{GA}$ is implemented as a computer simulation in which a population of abstract representations (called as genome or the genotype or chromosomes) to an optimisation problem fitness is associated to the value of one.

Fitness $=\frac{1}{1+O F}$

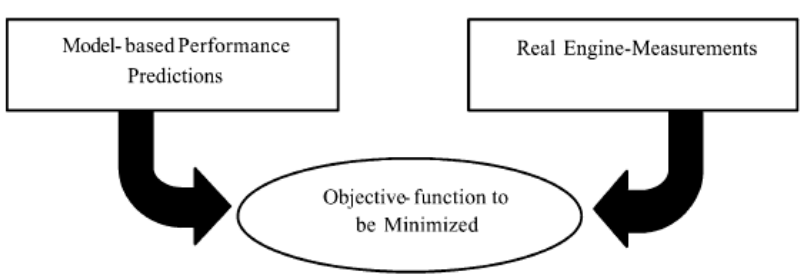

Fig. 5. The objective function [48]

The GA is operating over a wide number of iterations, each one of them consists, the following fundamental $[20,47,48]$ :

- A selection is a process where stings are assessed according to a 'survival of the fittest' criterion and selectively copied to be used in the next generation.

- A crossover is a process that permits information exchange between strings in the form of swapping of parts of the parameter vector, so as to produce fitter strings from the current population.

- The mutation operation randomly alters part of existing individuals without exceeding the pre- decided upper and lower thresholds to produce new individuals.

The number of GA generations and the size of population determine the accuracy of searched results and the speed of search, thus the selection of these GA parameters should be a compromise between the accuracy and speed [27].

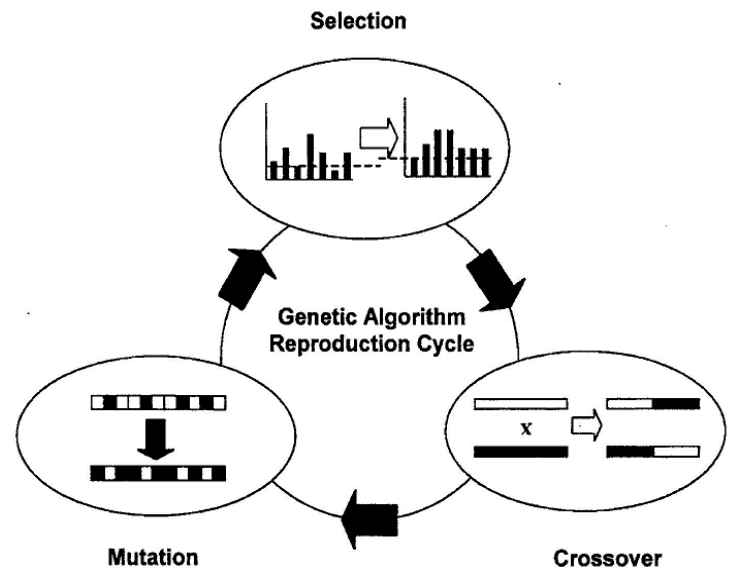

Fig.6. GA re-production cycle [46]

\subsection{Artificial Neural Network}

Artificial Neural Network (ANN) or Neural Network (NN) began in 1943 [28] and showed that it was possible to construct a network using only mathematics and algorithms. Neural Network found application in aircraft engine diagnostics by Dietz [27], space main engine by Whitehead [30,31] and an increasing number of other fields [32]. The Neural Network approach is a non-linear estimator that attempts to simulate the learning process performed by the brain, making it effective at pattern recognition [62-65]. According to [33], the NN is a mathematical structure that distributes input data into several interconnected simple units (the artificial neurons), separating the fault diagnosis into two phases: identifying the faulty component(s) and proceeding to quantify the fault. For example, Fig. 7 pictures the inputs of the $\mathrm{NN}$ which are the changes in the measurable parameters, whereas the outputs are the resulted shifts in some gas turbine components characteristics [6669].

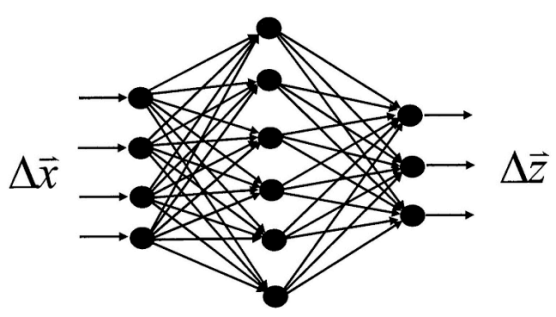

Fig. 7. A neural network for fault quantification [95]

The NN structure in Fig.7 demonstrates that the data within neurons processed in parallel system and its functionality is determined by the network structure and connection strengths [32]. Because of their high connectivity and parallelism, NN is able to link, in a non-linear way, a multidimensional input space with a multi-dimensional output space, allowing very high computational speed [33]. This technique is capable of simulating the functional relationship 
between dependent and independent variables by adapting and storing experimental knowledge in the network (which is the training phase) and can be configured to be tolerant of noise in the measured or training-data sets. The stopping criterion for the $\mathrm{NN}$ training phase is the minimization of a performance function or the mean-square error on the whole training set between the target and the corresponding $\mathrm{NN}$ computed outputs [32].

\subsection{Bayesian-Belief Network}

Bayesian-Belief Network (BBN) is a powerful tool for fault identification in gas turbines and based upon formal probability theory [74-76]. It is a system that integrates test measurements and gas path analysis program results with information regarding operational history and direct physical observation, helping for a cost effective diagnosis and using value of information calculations [36]. More generally, BBN is a graphical representation of a probability distribution which encodes the cause and effect relationships between particular variables represented as nodes and arches. Each node represents an observation or a fault that contains the conditional probability that describes the relationship between the node (effects) and the parents (causes) of that node. Kedamb at [37], designated the health parameters as the parent nodes and the measurements as the child nodes. If a particular child node is affected by the fault the link between parent and child node is established as the illustrated example in Fig.8.

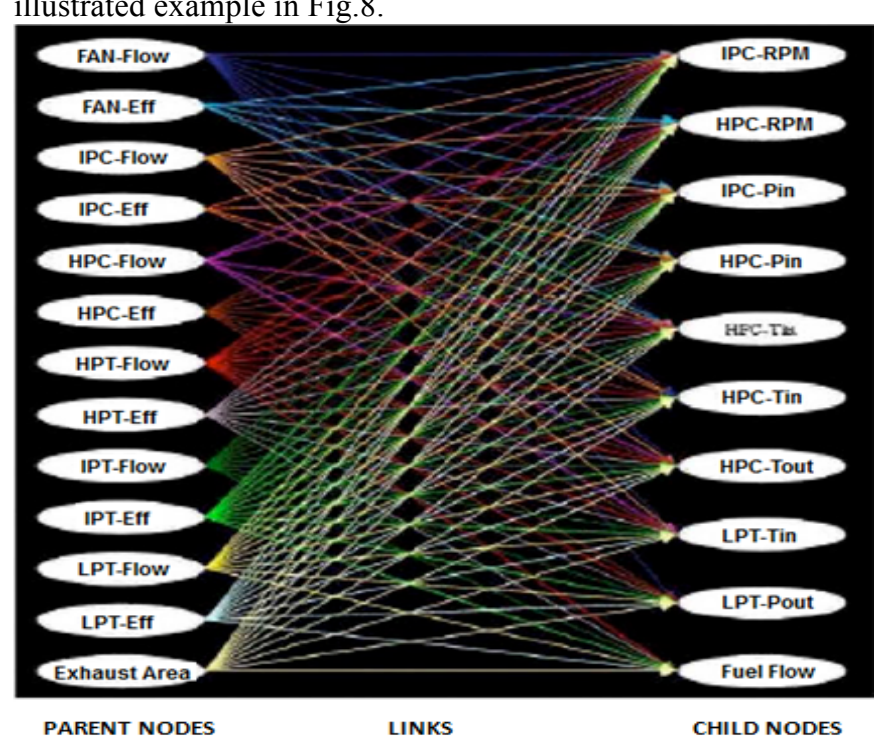

Fig. 8. Typical BBN layout [35]

\subsection{Expert Systems}

Expert systems have been in use for medical diagnosis for over 30 years so far, and since there are direct comparisons between medical and technical diagnosis, it was decided to build an expert system to diagnose engine faults [70-73]. Expert systems are defined as a computer program designed specifically to simulate a specialist human engineer's ability to problem-solve or giving advice(s). Expert systems use sophisticated problem-solving techniques and vast stores of organised knowledge, concerning a definite area of expertise to solve problems justify its own line of reasoning, and to act on deductions just as human would. Instead of being programmed to follow step-by-step procedures, expert systems uses facts about the problem supplied by a user, plus its knowledge base and general problem solving procedures to find and apply a specific solution. The main components of an expert system, as illustrated in Fig.9, are:
- The inference engine which deals with all the reasoning operations of the system.

- The knowledge base which contains the inference rules and facts that the expert system has been taught about the problem by the human tutor.

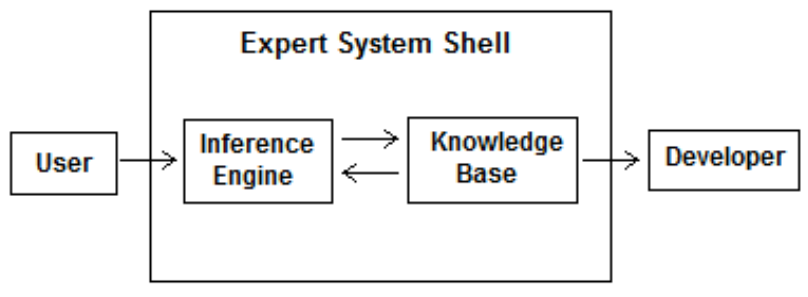

Fig. 9. Typical Expert System layout

\subsection{Fuzzy Logic Systems}

Fuzzy logic systems (FLS) were introduced by L.Zedah at University of Berkeley in 1960 as means to model the uncertainty of natural language. Historically, FLS has been used to identify and isolate the faulty components rather than the degree of deterioration $[51,77,82]$, however, they were used to determine when to service the T700 engine [36]. FLs are defined as a method to formalise the human ability to reason approximately and judge under uncertain conditions [39]. The primary benefit of FL is to approximate system behaviour, where analytical functions or numerical relations do not exist [40]. Therefore, they have the potential to understand complex systems that have not been tested or that do not have a vast array of data available on them, such as the gas path diagnostics of gas turbines [41]. A typical FLS design may consists of:

- Fuzzifiation; the process of converting crisp ordinary values into degrees of membership to predefined fuzzy input set $[38,39]$.

- Rule evaluation or fuzzy inference engine; maps fuzzy input sets to fuzzy output sets.

- Defuzzification; a scalar quantity is delivered from the fuzzy outputs when crisp numbers are needed as an output of the fuzzy logic system.

- A knowledge base includes fuzzy rules and functions that play a key role in the fuzzy inference process.

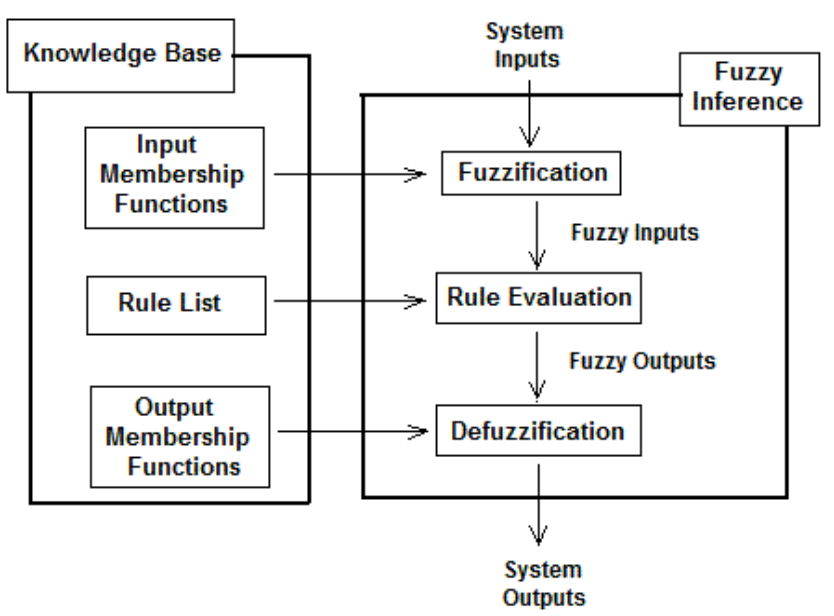

Fig. 10. Typical FLS layout 


\subsection{Weighted-Least-Squares}

Weighted-Least-Squares (WLS) algorithms are linear but often employ non-linear extensions to identify largemagnitude faults. WLS emphasize correct determination of the faulted component, while placing less emphasis on getting the magnitude right [38]. They do not seek to find a single true solution but instead a solution with the highest probability of being near to the one, true solution. Therefore, WLS tries to find a function that closely approximates the data for a best fit and is weighted such that points with a greater weight contribute more to the fit. In order to account for the fact that some measurements are more accurate than others, it may be necessary to place more weight on the more accurate readings and less on the accurate measurements.

\section{Discussion}

An overview of the most common GPA techniques is presented, with the intention of highlighting some of the most important advantages and disadvantages for each diagnostic tool according to [20, 42-46].

\section{Linear/Non-Linear GPA}

Advantages:

- Faults can be isolated at component level by means of calculations of the corresponding performance parameters variations.

- Diagnosis can be performed in more than a single engine component.

- Calculations of the performance allow quantification of the fault(s).

Disadvantages:

- Accurate assessment is complicated by only having relatively few measurements available and errors in the measurements.

- Linearization and iterative approaches can only handle the non-linearity.

- Larger number of sensors - for better predictions leads to higher costs.

$\underline{\text { Kalman Filter }}$

Advantages:

- Is recursive method; the memory requirements are minimised and thus the filter can deal with realtime data processing.

- It provides after each measurement an estimate of the errors in the parameter characterising the state of the system.

- The filter responds well to discontinuous changes (steps) in the measurements, without erratic transients occurring.

Disadvantages:

- If a systematic error is present as part of the measured signal then no amount of filtering will reduce this fixed error.

- KF may become unstable because either it contains too many small values or because the computer calculations have not been sufficiently accurate.

- The apriori estimate is a reasonable guess and has to be close to the true value for the residuals to be small and hence higher degree of accuracy.

- The smearing effect is present and the concentration on the faulty components may be difficult.

Generic Algorithms
Advantages

- The inductive nature of the GA means that it doesn't have to know any rules of the problem, since it works by its own internal rules. This characteristic is very useful for complex or loosely defined problems.

- $\quad$ It can quickly scan a vast solution set.

- Bad proposals do not affect the end solution negatively as they are simply discarded.

Disadvantages

- Evolution is inductive; in nature life does not evolve towards a good solution, it evolves away from bad circumstances and therefore GAs risk finding a suboptimal solution.

- As population and generation number grows, longer computation time required.

Neural Network

Advantages

- Able to deal with large non-linearity degradations and instrumentation faults.

- Using the information of data for training, makes the network suited for solution to the problems where no exact algorithmic solutions exist but large number of examples.

- Very good data fusion technique; different kind of data such as vibrational, thermodynamic and electrostatic, are allowed to be used to produce an answer.

- Can be trained to recognise noisy measurements to interpret them accordingly.

Disadvantages

- The period of the system training is highly timing consuming.

- Difficulties when diagnosing faults with noisy data.

- $\quad$ Requires good quality data for the training phase.

- Needs time to be retrained if model engine hardware changes.

Bayesian-Belief Network

Advantages

- Different types of data (qualitative, continuous numbers or discrete numbers) are accepted.

- Diagnosis can be performed in more than a single engine component.

- $\quad$ No mathematical relationships are required to build a BBN, but only the way variables affect to each other.

- Changes of the model engine hardware can be easily entered in the network because any addition or removal of a node can be made, without the need to rebuild the whole network as BBN are local distributions.

Disadvantages

- Needs substantial time and big effort to gather information needed for setting up a data base.

- Requires an expert or someone familiar with this network to make any change in a timely manner.

- Bayesian belief network is combined with the results of GPA hence some of the drawbacks of GPA would be inherently present in such a system.

- Cannot deal with sensor bias.

\section{Expert Systems}

Advantages 


\section{Journal of Engineering Science and Technology Review 8 (4) (2015) 64- 72}

- Constant availability of expert advice eliminates any waiting for the expert's time even in a remote or harsh environment.

- They represent the knowledge of a group as a whole and thus there is a elimination of individual bias, prejudice and errors due to oversight or fatigue.

Disadvantages

- $\quad$ The human experts are often in short supply and as such are often expensive to maintain reflecting the large investment in time and money required to establish this high level of expertise.

\section{Fuzzy Logic Systems}

Advantages

- Supports the generation of a fast prototype and incremental optimization.

- $\quad$ The intelligence of the system is not involved with differential equations or source code and thus remains simple to understand.

- The feature of the model-free allows data-fusion and reductions in computational time.

Disadvantages

- Unable to approximate faults that occur outside range of data that they have already been set up to tackle.

- The achieved accuracy is a compromise between the computational speed in producing the required output and the effort expended by the designer in formulating the rules.

- The number of rules increases according to the complexity of the process that is being approximated.

\section{Weighted-Least-Squares}

\section{Advantages}

- Constant availability of expert advice eliminates any waiting for the expert's time even in a remote or harsh environment.

- They represent the knowledge of a group as a whole and thus there is a elimination of individual bias, prejudice and errors due to oversight or fatigue.

- It uses fewer equations than it has values to find.

Disadvantages

- Prior knowledge and tuning is needed.

- $\quad$ The WLS algorithm tends to smear the fault over many components; thereby the isolation of the faulty component becomes difficult.

- The assumed approximation to the linear model may reveal a larger error than anticipated.

\section{Conclusion}

Apparently, every technique has its own advantages and limitations but it would be interesting to list the characteristics of a theoretically ideal technique that may exist in the future. These characteristics of the hypothetical diagnostic tool introduced in 2004 by L. Marinai et al. [20] and presented as it follows:

- Based on a non-linear model.

- Capable of detecting even small changes in performance with reasonable accuracy.

- Able to deal with measurement noise and sensor bias.

- Diagnose with high accuracy, by using measurements less than the number of health parameters $(\mathrm{N}>\mathrm{M})$.

- Designed specifically for single or multiple fault isolation.

- Avoid any smearing effect and possess a concentration capability on the actual fault.

- No need for any training and tuning uncertainties, difficulties and dependencies for the setting-up parameters.

- It is model-free that allows data-fusion and reductions in computational time.

- Competent to incorporate expert knowledge.

\section{Nomenclature}

$\begin{array}{ll}\text { Acronyms } & \\ \text { DMI } & \text { - Direct Matrix Inverse } \\ \text { FCM } & \text { - Fault Coefficient Matrix } \\ \text { FOD } & \text { - Foreign Object Damage } \\ \text { GPA } & \text { - Gas Path Analysis } \\ \text { ICM } & \text { - Influence Coefficient Matrix } \\ \text { RMS } & \text { - Root Mean Square } \\ \text { SFC } & \text { - Specific Fuel Consumption } \\ \text { TET } & \text {-Turbine Entry Temperature }\end{array}$

\section{Notations}

$\Delta \mathrm{z} \quad$ - Performance Parameters Deviation

$\Delta \mathrm{x} \quad$ - Engine Module Parameters Deviation

\section{Subscripts}

$\begin{array}{ll}\vec{z} & \text { - Dependent parameter vector } \\ \vec{x} & \text { - Independent (component) parameter vector } \\ \vec{w} & \text { - Environmental variables vector (i.e. ambient } \\ \text { pressure, temperature) }\end{array}$

\section{References}

1. Ntantis E.L. Capability Expansion of Non-Linear Gas Path Analysis, Ph.D. Thesis, Cranfield University, England, 2008.

2. Diakunchak I.S. Performance deterioration in industrial gas turbine, Journal of Engineering for Gas Turbines and Power, Vol. 114, No. 2, pp. 161-168, 1992.

3. Lakshminarasimha A.N., Boyce M.P. and Meher-Homji C.B. Modelling and analysis of gas turbine performance deterioration, Journal of Engineering for Gas Turbines and Power, Vol. 116, No. 1, pp. 46-52, 1994.

4. Hamed A., Tabakoff W. and Singh D. Modelling of compressor performance deterioration due to erosion, International Journal of Rotating Machinery, Vol. 4 Issue 4, pp. 243-248, 1998.
5. Tabakoff W., Lakshminarasimha N. and Pasin M. Simulation of compressor performance deterioration due to erosion, Journal of Turbomachinery 112 (1) pp 78-83, 1990.

6. Merrington G., Kwon O.K., Goodwin G. and Carlsson B. Fault detection and diagnosis in gas turbines, Journal of Engineering for Gas Turbines and Power, Vol. 113, No. 2, pp. 276-282, 1991.

7. Ntantis E. L., Li Y.G. The impact of measurement noise on gas turbine GPA diagnostics. The $6^{\text {th }}$ International Conference on Condition Monitoring \& Machinery Failure Prevention Technologies, Dublin, Ireland, June 23-25, 2009.

8. Ntantis E. L., Li Y.G. The impact of measurement noise in GPA diagnostics analysis of a gas turbine engine, International Journal of Turbo \& Jet Engine. Vol. 30 (4), pp. 401-408, 2013. 


\section{Journal of Engineering Science and Technology Review 8 (4) (2015) 64- 72}

9. Dyson R.J.E., Doel D.L. CF6-80 condition monitoring - The engine manufacturer's involvement in data acquisition and analysis, AIAA-1984-1412, SAE, and ASME Joint Propulsion Conference, 20th, Cincinnati, OH, June 11-13, 1984.

10. Roemer M.J. Testing of a real-time health monitoring and diagnostic system for gas turbine engine, AIAA-1998-3603, AIAA/ASME/SAE/ASEE Joint Propulsion Conference \& Exhibit, 34th, Cleveland, OH, July 13-15, 1998.

11. Escher P.C. Pythia: An object oriented gas path analysis computer program for general applications, Ph.D. Thesis, Cranfield University, England, 1995.

12. Ogaji S.O.T., Sampath S., Singh R. and Probert S.D. Parameter selection for diagnosing a gasturbine's performance-deterioration, Journal of Applied Energy, Vol. 73, No. 1, pp. 25-46, 2002.

13. Agrawal R.K., MacIsaac B.D. and Saravanamutoo H.I.H. An analysis procedure for validation of on-site performance measurements of gas turbines, ASME, Journal of Engineering for Power, Paper No. 78-GT-152, 1978.

14. Aker G.F. and Saravanamutoo H.I.H. Predicting gas turbine performance degradation behavior due to compressor fouling using computer simulation techniques, ASME, Journal of Engineering for Power, Vol. 111, No. 2, pp. 343-350, 1989.

15. Ghenaiet A., Tan S.C. and Elder R.L. Experimental investigation of axial fan erosion and performance degradation, Journal of Power and Energy, Vol. 218, No. 6, pp. 437-450, 2004

16. Batcho P.F., Moller J.C., Padova C. and Dunn M.G. Interpretation of gas turbine response due to dust ingestion, ASME Journal of Engineering for Gas Turbines and Power, Vol. 109, No. 3, pp. 344$352,1984$.

17. Macleod J.D., Taylor V. and Laflamme J.C.G. Implanted component faults and their effects on gas turbine engine performance, Journal of Engineering for Gas Turbine and Power, Vol. 114, Issue 2, pp. 174-179, April 1992.

18. Urban L.A. Gas turbine engine parameter interrelationships, Hamilton Standard Division, United Aircraft Corporation, 1969.

19. Urban L.A. Parameter selection for multiple fault diagnostics of gas turbine engines, AGARD CP-165, also ASME Paper 74-GT-62, Journal of Engineering for Power, pp. 225-230, 1975.

20. Marinai L., Probert D. and Singh R. Prospects for aero gas-turbine diagnostics: A review, Journal of Applied Energy, Vol. 79, pp. 109126, 2004.

21. Li Y.G., Pilidis P. And Newby M.A. An adaptation approach for gas turbine design-point performance simulation, Journal of Engineering for Gas Turbines and Power, Vol. 128, Issue 4, pp. 789-795, October 2006

22. Kalman R.E. A new approach to linear filtering and prediction problems, ASME Transaction: Journal of Basic Engineering, Vol. 82, Series D, pp. 35-45, March 1960.

23. Kalman R.E. and Bucy R.S. New results in linear filtering and prediction problems, ASME Transaction: Journal of Basic Engineering, Vol. 83, Series D, pp. 95-108, March 1961.

24. Shet K.C. and Rao B.V. An overview of the Kalman algorithm, International Journal of

Electronics, Vol. 59, No. 6, pp. 657-665, 1985.

25. Volponi A.J., DePold H., Ganguli R. and Chen D. The use of Kalman filter and neural network methodologies in gas turbine performance diagnostics: A comparative study, ASME 2000-GT547, ASME TURBO EXPO 2000, Munich, Germany, May 2000.

26. Walsh G. and Bishop G. An introduction to the Kalman Filter, UNC-Chapel Hill, TR 95-041, 24 July 2006.

27. Gatto E.Lo., Li Y.G. and Pilidis P. Gas turbine off-design performance adaptation using a genetic algorithm, International 51st ASME Turbo Expo, Barcelona, Spain, 2006.

28. McCulloch W. and Pitts W. A Logical Calculus of the Ideas Immanent in Nervous Activity, Bull.Math. Biophysics, Vol. 5, pp. 115-37, 1943.

29. Dietz W.E., Kiech E.L. and All M. Jet and rocket engine fault diagnosis in real time. Journal of Neural Network Computing, Vol. 1, No. 1, pp. 5-18, 1989.

30. Whitehead B.A., Ferber H.J. and Ali M. Neural Network Approach to space shuttle main engine health monitoring, AIAA/ASME/SAE/ASEE 26th Joint Propulsion Conference, July 1990, American Institute of Aeronautics and Astronautics, Paper 90-2259, 1990.

31. Bhushan M. and Raghunathan R. Design of sensor location based on fault diagnostic observability and reliability criteria, Computers and Chemical Engineering 24 (2-7), pp. 735-741, 2000.
32. Haykin S. Neural Networks: A Comprehensive Foundation, MacMillan College Publishing Company, New York, 1994.

33. Singh R. Gas turbine applications, MSc Course Notes, Cranfield University, England, 2004

34. Bettocchi R., Pinelli M., Spina P.R. and Venturini M. Artificial intelligence for the diagnostics of gas turbines - Part I: neural networks approach, Journal of Engineering for Gas Turbines and Power, vol. 129, pp. 771 - 719, 2007.

35. Haykin S. Neural Networks: A Comprehensive Foundation, 2nd Edition, Prentice-Hall,

Englewood Cliffs, NJ, 1999.

36. Palmer C.A. Combining Bayesian belief networks with gas path analysis for test cell diagnostics and overhaul, International Gas Turbine and Aero Engine Congress \& Exhibition, Stockholm. Sweden, ASME-98-GT-168, 1998.

37. Kadamb A. Bayesian belief network for aero gas-turbine model and system fault isolation, MSc Thesis, Cranfield University, England, UK, 2003.

38. Karvounis G. and Frith P. Automated detection of engine health using hybrid model-based and fuzzy logic approach, ISABE 20031232, 16th International Symposium on air breathing engines, Cleveland, Ohio, 31-Aug-5 Sept, 2003.

39. Ross T.J. Fuzzy logic with engineering applications, Second Edition, John Wiley \& Sons, 2004.

40. Kosko B. Fuzzy thinking, Harper Collins Publishers, Hammersmith, England, 1994.

41. Siu C., Shen Q. and Milne R. Reinforcing fuzzy rule-based diagnosis of turbo machines with case-based reasoning, IPS Press, vol. 12, no. 2, pp. 173-191, 2008.

42. Zedda M. and Singh R. Gas turbine engine and sensor faultdiagnosis using optimization techniques, Journal of Propulsion \& Power, vol. 18, no. 5, pp. 1019-1025, 2002.

43. Urban LA. and Volponi A.J. Mathematical methods of relative engine performance diagnostics. SAE 1992 Transactions Journals of Aerospace, Section 1, vol. 101, SAE Technical Paper no.922048, 1992.

44. Cooper W.S. Use of optimal estimation theory, in particular the Kalman filter, in data analysis and signal processing, Review of Scientific Instrumentation, vol. 57, no. 11, pp. 2862-2869, November 1986.

45. Volponi A.J. Sensor error compensation in engine performance diagnostics, ASME, 94-GT-58, 1994.

46. Doel D.L. Interpretation of weighted-least-squares gas path analysis results, Journal of Engineering for Gas Turbines and Power, vol. 125 , no. 3, pp. 624-633, 2003.

47. Suresh S., Ogaji S., Singh R. and Probert D. Engine-fault diagnostics: An optimisation procedure, Journal of Applied Energy, vol. 73, issue 1, pp. 47-70, September 2002.

48. Li Y.G. Performance-analysis-based gas-turbine diagnostics: A review, Proceedings of the Institute of Mechanical Engineering, Part A: Journal of Power and Energy, vol. 216, no. A5, 2002.

49. Donaghy M.J. Gas path analysis - Fault diagnosis using DETEM, MSc Thesis, Cranfield University, England, 1991.

50. Zedda M. Gas-turbine engine and sensor fault diagnosis, PhD Thesis, Cranfield, University, England, 1999.

51. Ganguli R. Data rectification and detection of trend shifts in jet engine gas path measurements using median filters and fuzzy logic, Proceeding of ASME, Turbo Expo 2001, June 4-7, 2001, New Orleans, USA, 2001-GT-0014, 2001.

52. Urban L, Parameters selection for multiple fault diagnostics of gas turbine engines, Journal of Engineering for Power, vol. 4, issue 4, pp.225-230, 1975.

53. Urban L. A. and Volponi A. J., Mathematical methods of relative engine performance diagnostics, SAE Technical paper series, 1992.

54. Volponi A.J., Brotherton T., Luppold R. and SimonD. L., Development of an information fusion system for engine diagnostics and health management, AIAA 2004-6461, AIAA 1st Intelligent Systems Technical Conference, Chicago, Illinois, 2004.

55. Volponi A., DePold H., Ganguli R., and Daguang C., The use of Kalman filter and neural network methodologies in gas turbine Performance Diagnostics: A comparative study, Journal of Engineering for Gas Turbines and Power, vol. 125, pp.917, 2003.

56. Simona D., Simonb D. L., Constrained Kalman filtering via density function truncation for turbofan engine healthe estimation, International Journal of Systems Science, vol. 41, issue 2, pp.159$171,2009$.

57. Jose R. Celaya Abhinav S. and Kai G., Uncertainty representation and interpretation in modelbased prognostics algorithms based on 


\section{Journal of Engineering Science and Technology Review 8 (4) (2015) 64- 72}

Kalman filter estimation. Annual conference of the prognostics and health management society 2012, vol. 3. Minneapolis USA, 2012.

58. Kobayashi T. and Simon D. L., Application of a bank of Kalman filters for aircraft engine fault diagnostics, ASMS Turbo Expo 2003, Atlanta Georgia, USA Number GT2003-38550, pp. 461-470, 2003.

59. Luppold R., Roman J., Gallops G. and Kerr L., Estimating in-flight engine performance variations using Kalman filter concepts. AIAA/ASMS/SAE/ASEE Joint Propulsion Conference, 25th Monterey, CA, USA, 1989.

60. Xujun Han and Xin Li, An evaluation of the nonlinear/nonGaussian filters for the sequential data assimilation, Remote Sensing of environment, vol.112, pp. 1434-1449, 2008.

61. Lall P., Junchao Wei and Goebel K., Comparison of Kalman-filter and extended Kalman-filter for prognostics health management, Thermal and thermomechanical phenomena in electronic systems (IThem), 13th IEEE Intersociety Conference on, pp. 1281, 2012.

62. 62. Yoon J. E., Lee J. J., Kim T. S., and Sohn J. L., Analysis of performance deterioration of a micro gas turbine and the use of neural network for predicting deteriorated component characteristics, Journal of mechanical science and technology, vol. 22, no. 22, pp. 2516-2525, 2008.

63. Tang G., Yates C. L. and Chen D., Comparative study of two neural networks applied to jet engine fault diagnosis, AIAA/ASME/SAE/ASEE Joint propulsion conference \& exhibit, $34^{\text {th }}$ Cleveland, OH, 1998.

64. Ogali S.O.T. and Singh R., Advanced engine diagnostics using artificial neural networks, Journal of Applied Soft Computing, vol.3 Issue 3, pp. 259-271, 2003.

65. Chen T. and Sun J. G., Rough set and neural network based fault diagnosis for aeroengine gas path. ASMS Turbo-Expo 2005: Power for Land, Sea and Air (GT2005), June 6-9-2005, Remo, Nevada, USA, 2005.

66. Fast M., Assadi M. and De S., Development and multi-utility of an ANN model for an industrial gas turbine, Journal of Applied Energy, vol. 86, no. 1, pp. 9-17, 2009.

67. Kanelopoulos K., Stamatis A. and Mathioudakis K., Incorporating neural networks into gas turbine performance diagnostics, The 1997 International gas turbine \& Aero-engine congress \& exposition, Orlando, FL, USA, pp. 8. June 1997.

68. Ogali S.O.T., Li Y.G., Sampath S. and Singh R., Gas path fault diagnosis of a turbofan engine from transient data using artificial neural networks, ASME paper GT 2003-38423, ASME TURBO EXPO 2003, Atlanta Georgia, USA June 16-19, 2003.

69. Lu P. J., Zhang M. C., Hsu T.C. and Zhang J., An evaluation of engine faults diagnostics using artificial neural networks, Journal of Engineering for Gas Turbines and Power, Vol. 123, issue 2,pp. 340-346, 2001.

70. Afgan N., Cavalho M., Pilvachi P., Tourlidakis A., Olkhonski G. and Martins N., An expert system concept for diagnosis and monitoring of gas turbine combustion chambers, Journal of Applied Thermal Engineering, vol. 26 no. 7 pp. 766-771, 2006.

71. Shah R., LaPierre L., Costen P., Doel D., Co G. E. and Syracuse N., JET-X: jet engine troubleshooting expert system, Proceedings of the international workshop on artificial intelligence for industrial applications, pp. 135-139, 1988.

72. Tang G., Yates C. L., Zhang J. and Chen D., A practical intelligent system for condition monitoring and fault diagnosis of jet engines, AIAA/ASME/SAE/ASEE Joint Propulsion Conference and Exhibit, 35th, Los Angeles, CA. 1999.

73. Kopytov E., Labendik V. and Yunusov S. Expert systems for evaluating the aircraft power plants' technical condition, Journal of Transport and Communication, vol. 11, no. 1, pp. 31-37, 2010.

74. Romessis C., Stamatis A. and Mathioudakis K., Setting up a belief network for turbofan diagnosis with the aid of an engine performance model, International symposium on air breathing engines, 15th Bangalore, India, 2001.

97. ol. 100, pp. 691-697, 1978.
75. Romessis C., and Mathioudakis K., Bayesian network approach for gas path fault diagnosis. Journal of Engineering for Gas turbines and Power, vol. 128, issue 1, pp. 64-72, 2006.

76. Lee Y. K., Mavris D. N., Volovoi V.V., Yuan M. and Fisher T., A fault diagnosis method for industrial gas turbines using Bayesian data analysis, Journal of Engineering for Gas Turbines and Power, vol. 132, 2010.

77. Demirici S., Hajiyev C. and Schwenke A. Fuzzy logic-based automated engine health monitoring for commercial aircraft, Aircraft engineering and aerospace technology, vol. 80, no. 5, pp. 516- 525, 2008.

78. Gen M. and Cheng R., Genetic algorithms and engineering optimization, Wiley, New York, USA, 2000

79. Kyriazis A. and Mathioudakis K. Enhanced fault localization using probabilistic fusion with gas path analysis algorithms, Journal of Engineering for Gas Turbines and Power, vol.131, 2009.

80. Wei X., Guo Y., Aircraft engine sensor fault diagnostics based on estimation of engine's health degradation, Chinese Journal of Aeronautics, vol. 22, pp. 18-21, 2009.

81. Simon D., A comparison of filtering approached for aircraft engine estimation, Aerospace Science and technology, vol. 12, pp. 276284, 2008.

82. Applebaum E. and Ha'Emek M., Fuzzy classification for fault isolation in gas turbine engines. Joint 9th IFSA world congress and 20th NAFIPS international conference, vol. 1, pp. 292-297, 2001.

83. Mucino M. and Li Y., A diagnostics system for gas turbines using GPA-index, COMADEM Conference 2005-C007, 2005.

84. Stamatis A.G., Evaluation of gas path analysis methods for gas turbine diagnostics, Journal of Mechanical Science and Technology, vol. 25, issue 2, pp. 469-477, 2011.

85. Smith K., Health usage monitoring system, AHS/AIAA Specialists' meeting: airworthiness, CBM \& HUMS, 7 February, Huntsville, Alabama, AHS, USA, 2011.

86. Mathioudakis A. S., Papailiou K., and Smith M., Jet engine fault detection with discrete operating points gas path analysis, Journal of Propulsion and Power, vol. 7, pp. 1043-1048, 1991.

87. Lunderstaedt R. A. and Junk R. H., Application of the gas path analysis (GPA) for the nonstationary operation of a jet engine, ISABE-International symposium on air breathing engines, 13th Chattanooga TN, USA, pp 430-437, 1997.

88. Walsh P. P., Fletcher P., and InterScience W., Gas turbine performance, Blackwell Science Oxford, Maiden MA, 1998.

89. Simani S., Identification and fault diagnosis of a simulated model of an industrial gas turbine, IEEE Transactions on industrial informatics, vol 1, Issue 3, pp. 202-216, 2005.

90. 90. Provost M.J., The use of optimal estimation techniques in the analysis of gas turbines, PHD thesis, Cranfield University, School of Engineering, Bedfordshire, UK, 1994.

91. Provost M. J., COMPASS: a generalized ground-based monitoring system, AGARD-CP-449, Engine condition monitoring technology and experience, 1988.

92. Mucino M. Performance simulation and diagnostics for operations optimisation and risk management, $\mathrm{PhD}$ thesis, Cranfield University, Bedfordshire, England 2007.

93. Merrington G., Identification of dynamic characteristics for fault isolation purposes in a gas turbine using closed-loop measurements, AGARD-CP-448, Engine condition monitoring technology and experience, 1988.

94. Merrington G., Fault diagnosis of gas turbine engine from transient data, Journal of Engineering for Gas Turbines and Power, vol. 11, pp. 237-243, 1989.

95. Li Y.G. Gas Turbine Diagnostics, Lecture Notes. Cranfield University, 2008.

96. Lazalier G., Jacox J. and Reynolds E., A gas path performance diagnostic system to reduce J 75- P-17 engine overhaul costs, ASMS Transactions, Journal of engineering for Power, $\mathrm{v}$ 